\title{
A Review of Crisis Management Strategy and its Influences on the Organizational Performance
}

\author{
Mutassembellah A. A. Alzatari ${ }^{1}$, Sara Ravan Ramzani ${ }^{2}$ \\ Post Graduate Center, Limkokwing University of Creative Technology, Malaysia ${ }^{1,2}$
}

\begin{abstract}
Crisis Management is the choosing of an organized process, that is reasonably cost effective, in order to lessen certain threats facing the organization or company. It is a process coupled with the principle of sustainability. It is a measuring process, and one used to evaluate threats, and develop a strategy to manage it. These strategies include moving the threats elsewhere, avoiding them, and decreasing their negative impact, and accepting some or all of its effects. It indicates two options one which can occur. Undoubtedly the cases whereby there is only one chance are the cases where there are no threats. They are occurrences and events threaten the realization of goals, and could have a negative impact on the continuation of the work, thus making the crisis management a real art undertaken with competence, professionalism and experience. Threats are the chance that a company could face unexpected and unplanned losses, or could make the anticipated revenues fluctuate.
\end{abstract}

Keywords: Crisis, Crisis management, Strategy

\section{INTRODUCTION}

As organizations operating in today's society, it would at one time or the other witness instability in which the impacts of event(s) threaten its operations, survivals or reputation of organisations. The ability of such organization to successfully craft strategies to manage such crisis is what differentiate an organization that is able to manage instability state of affairs from another organization that allows such horrible state to dampen its strategic objectives [1]. Crisis management is therefore seen as the provision of an organization's preplanned, rapid response capability supported by a leadership, information management and communications capacity in an integrated fashion to enable fast decision making at a strategic level within a structured environment, and thereby allowing for effective recovery and protecting an organization's survival or reputation [2]. Also, it is imperative for the management to ensure that disasters do not happen or that the impact of critical situations be minimized [4].

A crisis is an unexpected event that causes stress, requires intervention, and mandates proper planning to ensure survival and sustainability in business [6]. These unplanned events may develop from natural disasters, terrorist activities, human error, or defective machinery. Damage to buildings, transportation devices, land, people, or finances could cause business operations to cease at a moment's notice. An organizational crisis involves a threat to the business, the element of surprise, and requires immediate decisions from company leaders [7].

\section{LITERATURE REVIEW}

\section{a. Organizational Crisis Management}

With the increase in frequency and complexity of organizational crises, the need for planned efforts to mitigate crisis events has become a serious concern for organizations. It is important to learn quickly from crisis events that actually occur. Organizational crisis management is understood as a series of procedures used to sustain or resume normal business operations, minimize stakeholder loss, and use learning to improve crisis management processes [8]. Crisis management typically includes steps that help to identify potential crisis signals or indicators, planning strategies, response coordination, and recovery plans. Heath (1998) observed that Western organizations typically adopted a fourstage model: prevention, preparation, response, and recovery PPRR. He viewed this model as interactive with opportunities for ongoing learning. Learning is considered as an axiomatic and critical recurrent feature of the majority of crisis management models. Among various models of crisis management, the one that was initially proposed by [10] appears to be the most comprehensive and representative of earlier and more current model articulations. Therefore, a brief review of each component in their model is provided. A full review of the crisis management model and related research can be found [11]. 


\section{International Advanced Research Journal in Science, Engineering and Technology}

Vol. 6, Issue 3, March 2019

\section{b. $\quad$ Effect of Crisis management on business}

Consistent with the findings of the literature review on Product [8], we found very few articles related to global crisis management. It is important to note the scope of this review reflects the focus of the call for this special issue. The scope is defined by studies that examine crises across different countries, what we can call comparative crisis research, as well as issues related to crisis management at multinationals. This differs from contextual crisis research that examines crisis management and communication practices in one country. Contextual crises seek to illumine practices that are country-specific and constitute a much larger body of research [14]. We are looking for research on how companies cope with crises that emerge in more than one country, and how multinationals are impacted by crisis management. For instance, an international crisis might involve the home country and one or more host countries or appear in number of host countries [15]. Based on our review of articles published in the 16 ISI listed journals we identified only eight articles.

\begin{tabular}{|c|c|c|}
\hline NO & Author/Year & Reason \\
\hline 1 & $\begin{array}{l}\text { Alserfee } \\
(2007)\end{array}$ & $\begin{array}{l}\text { - It is in the internal environment (Managers Characteristics, Managers } \\
\text { experience, Organizational characteristics). } \\
\text { - } \\
\text { in the external environment (Competitors ,Customers, Principles and values, } \\
\text { Owners, natural disasters. Government and trade unions }\end{array}$ \\
\hline 2 & $\begin{array}{l}\text { JAD ALLaH } \\
(2008)\end{array}$ & 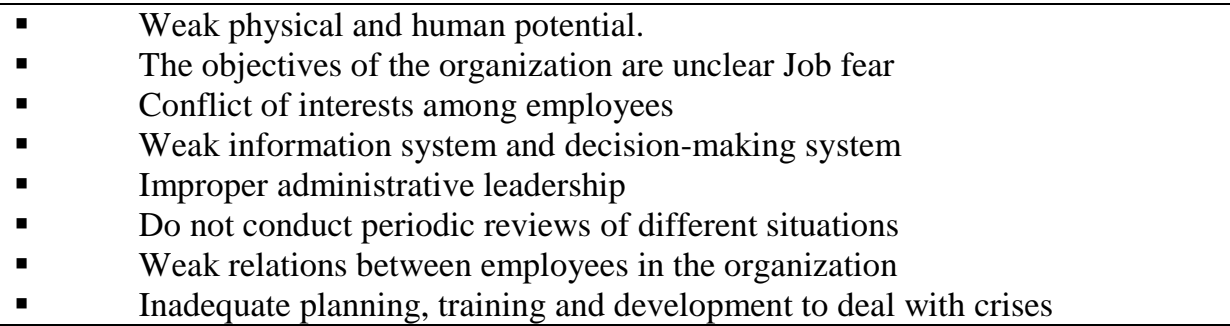 \\
\hline 3 & $\begin{array}{l}\text { Bundy, j, et al } \\
\text { (2017) }\end{array}$ & $\begin{array}{l}\text { - A misunderstanding (lack of information) Which leads to impulsive decision- } \\
\text { making or to judge a matter, before you find the truth. } \\
\text { - } \\
\text { that can be obtained, the estimated judgment on things presented, If the perception is } \\
\text { not correct, or resulted from the overlap of vision, It leads to a lack of safety direction } \\
\text { decided by the commander of the administrative entity. } \\
\text { - Misjudgment and poor evaluation, and fails optimism, which is one of the } \\
\text { most common causes of crises in all areas, It happens from two sides: Exaggeration, } \\
\text { overuse, And overconfident. For example, (to confront a party with another party } \\
\text { knowing in advance of the inability to confront). } \\
\text { - Misjudgment of the power of the other party, and underestimating it, and } \\
\text { reducing the party's complacency to another party, at the same time, } \\
\text { - } \\
\text { this party knows that the other side has the power. }\end{array}$ \\
\hline 4 & $\begin{array}{l}\text { Hearit,K.M } \\
(2006)\end{array}$ & $\begin{array}{l}\text { - Human errors: such as complacency, lack of motivation, lack of interest in } \\
\text { work, when you do not understand the relationship between different variables, this } \\
\text { helps the occurrence of the crisis, Such as ignoring available information, because its } \\
\text { confuse decision-maker, In this case follow what he likes to follow. } \\
\text { - Distorting information, by focusing on the information that the individual } \\
\text { need or the department, and denied and ignored any other information. } \\
\text { - Conflict of objectives, and this occurs through the difference of vision, and } \\
\text { ambitions between the decision-maker and the implementer beneficiary, which are } \\
\text { related to the crisis, they are as follows: } \\
\text { - } \\
\text { and information. } \\
\text { - } \\
\text { accordance with the organizational structure of the administrative entity, which is } \\
\text { responsible for the safety of this decision. } \\
\text { - } \\
\text { the necision executor: The individual entrusted with the process of carrying out } \\
\text { - } \\
\text { and represents the majority that surrounds the administrative entity. }\end{array}$ \\
\hline 5 & Boin (2008) & $\begin{array}{l}\text { Randomization management: This type of management does not function as a } \\
\text { gain for crises It also destroys the administrative entity. Random management is based }\end{array}$ \\
\hline
\end{tabular}




\section{International Advanced Research Journal in Science, Engineering and Technology}

Vol. 6, Issue 3, March 2019

\begin{tabular}{|c|c|c|}
\hline \multirow[b]{2}{*}{6} & & $\begin{array}{l}\text { on ignorance Encouraging deviations from the organization's main objective, and } \\
\text { relying on trends and the personal views of the manager, leading to the loss of the } \\
\text { future vision. } \\
\text { Conflict of objectives: This occurs as a result of divergence of vision, } \\
\text { ambition and objectives between implementers Decision in the administrative entity } \\
\text { and decision maker, leading to multiple trends or Slowdown in the implementation of } \\
\text { decisions, and the collapse of confidence in the decision-maker and thus exacerbate } \\
\text { the crisis and increased intensity of the crisis. } \\
\text { - Conflict of interest: one of the most important causes of crises at the local } \\
\text { level or international, as each State, group or individual has different interests, if these } \\
\text { interests are strongly opposed, the motive for the crisis emerges. }\end{array}$ \\
\hline & $\begin{array}{l}\text { Anis, R } \\
\text { (2015) }\end{array}$ & $\begin{array}{l}\text { Irritable chaos: Here lies the devastating crisis, and the management which } \\
\text { will be done by the decision-maker according to the dictates of the situation without } \\
\text { prior planning cconspiracy and blackmail: conspiring against the decision-maker and } \\
\text { making it under different pressures that may be paid Towards a crisis, as well as the } \\
\text { desire to blackmail by exploiting erroneous actions and whether it was made by the } \\
\text { decision-maker, whether secret or Known to a few individuals Forcing him to have } \\
\text { more wrongly and more harmfully. } \\
\text { - Despair, Despondency and Frustration: because of loss of desire and } \\
\text { motivation for work and development Because of the separation of the individual's } \\
\text { interest from the interests of the organization. } \\
\text { - Rumors: Rumors are launched in a certain way after the recruitment and } \\
\text { briefing it of Incorrect and questionable information, declared at a given time, and } \\
\text { surrounding environment and then prepare them in a certain way, by exploiting a } \\
\text { specific event to explode the crisis. } \\
\text { - strength and power show: such as scolding a supervisor in front of his } \\
\text { employees by the manager }\end{array}$ \\
\hline
\end{tabular}

\section{DISCUSSION AND RECOMMENDATION}

As stated at the beginning of our article, crises may result in both successes and failures for organizations. We content that organizations will have more success in dealing with and learning from crises when they consider capability and learning issues, as crisis management has become a defining feature of contemporary governance. In times of crisis, communities and members of organizations expect their public leaders to minimize the impact of the crisis at hand, while critics and bureaucratic competitors try to seize the moment to blame incumbent rulers and their policies. In extreme environment, policy makers must somehow establish a sense of normality, and foster collective learning from the crisis experience. In the face of crisis, leaders must deal with the strategic challenges they face, the political risks and opportunities they encounter, the errors they make, the pitfalls they need to avoid, and the paths away from crisis they may pursue. The necessity for management is even more significant with the advent of a 24-hour news cycle and an increasingly internet savvy audience with ever changing technology at its finger tips. Public leaders have a special responsibility to help safeguard society from the adverse consequences of crisis. Experts in crisis management note to concern themselves with all crisis phases; the incubation stage, the onset, and the aftermath. Crisis leadership then involves five critical tasks: sense making, decision making, and meaning making, terminating and learning. Conclusively, the survival and growth of any business organization depend on its people because a considerable proportion of the value of an organization is determined not just by the recruitment and training policies adopted by the organization but also by the way in which the structure and culture of the organization allow strategic human resources development. Although this task is a very difficult one to accomplish, a first and necessary step towards a remarkable success in this area begins with a good knowledge of what the employees need in terms of career development. This enables the organization to adapt its capacities and capabilities to channeling all its available resources towards meeting these needs in their various forms. Crisis management methods of a business or in an organization are called crisis management plan. The credibility and reputation of organizations is heavily influenced by the perception of their responses during crisis situations. The organization and communication involved in responding to a crisis in a timely fashion makes for a challenge in businesses. There must be open and consistent communication throughout the hierarchy to contribute to a successful crisis communication process. The related terms emergency management and business continuity management focus respectively on the prompt but short lined "first aid" type of response (e.g. putting the fire out) and the longer-term recovery and restoration phases (e.g. moving operations to another site). Crisis is also a facet of risk management, although it is probably untrue to say that crisis management represents a failure of risk management since it will never be possible to totally mitigate the chances of catastrophes occurring. 


\title{
International Advanced Research Journal in Science, Engineering and Technology
}

\author{
Vol. 6, Issue 3, March 2019
}

\section{REFERENCES}

[1]. Agha, Y. (2009). The Political Economy of Disaster Vulnerability: A Case Study of Pakistan Earthquake, 2005.

[2]. Agle, B. R., Mitchell, R. K., and Sonnenfeld, J. A. (1999). Who Matters to CEOs? An Investigation of Stakeholder Attributes and Salience, Corporate Performance, and CEO Values. The Academy of Management Journal, 42(5), 507-525.

[3]. Agor, W. H. (1989). Intuition in organizations: Leading and managing productively: Sage.

[4]. Agranoff, R., and McGuire, M. (2004). Collaborative public management: New strategies for local governments: Georgetown University Press.

[5]. Aguinis, H., and Kraiger, K. (2009a). Benefits of Training and Development for Individuals and Teams, Organizations, and Society. Annual Review of Psychology, 60, 451-474.

[6]. Aguinis, H., and Kraiger, K. (2009b). Benefits of training and development for individuals and teams, organizations, and society. Annual Review of Psychology, 60, 451-474.

[7]. Alexander, A., Kumar, M. and Walker, H., 2018. A decision theory perspective on complexity in performance measurement and management. International Journal of Operations \& Production Management.

[8]. Alfoqahaa, S., 2018. Critical success factors of small and medium-sized enterprises in Palestine. Journal of Research in Marketing and Entrepreneurship.

[9]. Ali, and Badar. (2010). Dynamics of circular debt in Pakistan and its resolution. The Lahore Journal of Economics, 15(2010), 61-74.

[10]. Ali, S. S., \& Badar, S. (2010). Dynamics of circular debt in Pakistan \& its resolution. The Lahore Journal of Economics, 15(2010), 61-74.

[11]. Alpaslan, Sandy, and Mitroff. (2009). Corporate Governance in the Context of Crises: Towards a Stakeholder Theory of Crisis Management. Journal of Contingencies and Crisis Management, 17(1), 38-49.

[12]. Amin Lotfi, (2005), Financial Analysis for Evaluation and Performance Review Investment in the bourse, Alexandria, and the university campus.

[13]. Amiraslani, H., Lins, K.V., Servaes, H. and Tamayo, A., 2017. A matter of Trust? The bond market benefits of corporate social capital during the financial crisis.

[14]. Amirkhani, A.H., Saremi, A.R. and Shahraspi, R., 2016. The Relationship between Structural and Content Dimensions of Organization with Crisis Communications Preparedness. Mediterranean Journal of Social Sciences, 7(3 S2), p.54.

[15]. Anis Rahman Manzoor Haq, 2015. Causes of the global financial crisis from an Islamic point of view Analysis of the causes of the crisis and their adaptation to legitimate provisions 3. Al-Madinah Usul-ul-Fiqh Studies | Journal of the International University of the Sciences of the Principles of Jurisprudence - Egypt, 1 (172).

[16]. Aragon, Isabel, and Raquel. (2003). Effects of training on business results1. The International Journal of Human Resource Management, 14(6), 956-980.

[17]. Arbab , Anwar Tabben Mohamed and Musharraf-Taher Ahmed Mohamed Ali, 2013. Impact of Strategic Planning on Crisis Management (Doctoral Dissertation, Sudan University of Science and Technology).

[18]. Ariss, and Sherman. (1989). Employee education and job performance: does education matter? Public Personnel Management, 18(1), 1-9.

[19]. Armstrong, G. (2005). Differentiation through people: How can HR move beyond business partner? Human Resource Management, 44(2), 195199.

[20]. Aroga, M. R. (2011). Corruption and Decentralized Public Governance. International Journal of Governance, 1(3), 626-639.

[21]. Ash, and Levine. (1985). Job applicant training and work experience evaluation: An empirical comparison of four methods. Journal of applied psychology, 70(3), 572.

[22]. Aziz, Anwar, Uddin, Amanat, Ayub, and Jadoon. (2013). Nutrition Comparison Between Genus of Apple (Malus Sylvestris and Malus Domestica) To Show Which Cultivar is Best for the Province of Balochistan. Journal of Asian Scientific Research, 3(4), 417-424. 